\title{
IRR: An Operational Risks Reduction Model for Population Resettlement
}

\author{
Michael M. Cernea
}

$\mathbf{T}$ his paper concisely describes a theoretical model of development-induced displacement and resettlement processes: the Impoverishment Risks and Reconstruction (IRR) model. This model is a conceptual and methodological tool apt to perform several essential functions in support of analytical and operational development work. This instrument enables project planners to focus from the outset on the poverty issues that are at the heart of involuntary resettlement. It does not add new tasks on top of the existing ones in preparing projects entailing resettlement. Instead, it saves efforts and increases effectiveness by (a) moving risk discovery upstream in project preparation, and (b) by helping reduce displacement, guiding early risk-elimination or riskreduction actions.

The main such functions for which the model can be employed are:

- a predictive function, to anticipate the main impoverishment risks involved in forced displacement and resettlement;

- a diagnosticfunction, to help assessin thefield the content and the intensity of each major risk, in a given project's context;

- a planning and problem-resolution function, to guide the design of counter-risk measures and their incorporation in resettlement planning, for either preventing or mitigating risks; and

- a research function, to serve as methodology in the scholarly analysis of resettlement impacts and to guide monitoring and evaluation studies on resettlement processes.

As a theoretical model, the IRR also makes the linkage between the conceptual apparatus used in the analysis of displacement processes, on the one hand, and the theory of poverty, impoverishment prevention and poverty reduction, on the other side.

Knowledge has forewarning power. The research utility of the IRR Model results from using the knowledge about past processes, which is accumulated, 'packaged' and synthesized in the model. This research utility also comes from its ability to guide data collection in the field and to coherently aggregate disparate empirical findings along key variables. In the practice of planning or executing projects, the use of the IRR Model can help prevent, or at least mitigate and gradually reverse, the impoverishment risks embedded in development projects that involve involuntary resettlement.

Theoretical modeling in resettlement research has been made possible by the vast body of empirical findings generated worldwide by numerous researchers about the adverse consequences of forced displacement. The accumulation of empirical data enables us to reveal basic regularities within a multitude of similar and comparable processes. In forced displacement, the dominant regularity is the impoverishment of most resettlers. This impoverishment is deconstructed and explained in the IRR Model, which also outlines the key reconstruction strategies to counteract impoverishment.

The IRR Model has been formulated in the early 1990s (Cernea 1990) and has been considerably refined since (Cernea and McDowell 2000). During recent years, the model has been widely discussed in the development literature (e.g., see Mathur and Marsden 1998; Mahapatra 1999) and has become the leading conceptual model in resettlement research.

\section{Basic concepts}

At the core of the IRR Model are three basic concepts: risk, impoverishment andreconstruction. Therelated aspects of risks in development and risk-related social behavior can be addressed with a set of more specific, narrower and focused risk concepts such as: riskexposure, risk aversion, risk prevention, risk taking, risk reduction, risk reversal, risk coping, and others. The theoretical underpinnings of the Impoverishment Risks and Reconstruction Model are informed by sociology, economics, anthropology and ethics-more specifically by concerns for equity, human rights and social justice in development, rather than by economic efficiency alone.

\section{Resettlement needs and trends}

Involuntary population displacement results from the imperative need to build modern industrial and transportation infrastructure, expand power generation and irrigation, implement urban renewal and enhance social services-schools, hospitals, 
water supply. Nonetheless, by its adverse effects, forced population displacement remains a social pathology of development, and the first efforts must always be to avoid displacement wherever possible. Unfortunately, however, increases in population density, tight land scarcities and growing socioeconomic needs will maintain resettlement as a continuous companion of development. During the last two decades of the twentieth century, the magnitude of forced population displacements entailed by development projects was estimated at about 10 million people annually, or some 200 million people over two decades. Currently, in the first decade of the new century, the size of development-caused displacement is estimated at about 15 million people annually. This clearly indicates the global dimension of this social pathology.

\section{Decapitalization of resettlers}

In developing countries (to which this article mainly refers) forced resettlement carries severe risks of impoverishing the uprooted people, many of who are very poor even before displacement. Socioanthropological research currently documents that resettlement operations tend to cause the decapitalization and pauperization of vast numbers of resettlers. They lose capital in all its forms: natural capital, man-made physical capital, human capital and social capital. Eliminating or mitigating such impoverishment risks and improving resettlers' livelihoods is incumbent upon governments, agencies and private-sector corporations responsible for projects that cause forced-displacement.

\section{Poverty reduction policies}

If development's fundamental objective is to reduce poverty and promote growth, then development policies must attempt, among other goals, to minimize resettlement occurrences and (when resettlement is unavoidable) to carry out impoverishment-free relocation.

This paper argues that the orientation towards reducing the existing poverty must go hand in hand with efforts forpreventing the onset of new processes of impoverishment. Development itself is not freefrom risks and adverse impacts. Such risks of potential impoverishment regularly surface in development projects that require involuntary resettlement, and sometimes in other projects as well. If project planning and execution fail to anticipate the potential risks, and to prevent them from becoming reality, severe problems in resettlement operations will inevitably occur. This is why the socio-economic and moral principles embedded in poverty reduction policies must be translated in targeted actions oriented against adverse impacts and against new impoverishment processes.

In project practice, resettlement plans (RP) are required as mandatory in most internationally assisted projects. However, they are far less frequently mandated by governments of developing countries in projects they finance from domestic sources alone. Therefore, the requirement for explicit, adequately financed and culturally sensitive RPs must be generalized in all countries.

The currently used analytical and planning tools are often not sharp and flexible enough to lead to differentiated and effective responses to risks. Improving the analytical methodology for regular risk assessment is therefore indispensable and should result in the formulation of specific risks management actions.

\section{Usefulness of IRR in planning}

Applying the IRR conceptual template to the circumstances of each development project has several advantages:

- it ensures-most importantly-that no major risk to resettlers is overlooked during the feasibility analysis of planned developments;

- it prompts planners to distinguish the different intensity of each risks (high risks from low or moderaterisks, in a given projectcontext), rather than treating all risks uniformly; and

- it demands a pro-active risk-reversal orientation in project design, planning, financing and implementation.

The deconstruction of the impoverishment process into a template of eight basic risks permits the mobilization of proportionate resources for the highest risk or against the risks affecting larger numbers of people, while allocating less to risks with lower incidence or intensity in a certain context. In practice, this differential approach may vastly increase equity by rationalizing resource allocation. Early risk analysis may also conclude that in some projects one or another of the IRR Model's risks is not likely to occur. It can also reveal some locally specific risks that are not part of the template but need to be addressed.

\section{The major risks of impoverishment}

The IRR Model captures impoverishment not only in terms of 'income-poverty', but also in terms of losing employment opportunities, shelter, health, nutrition, education or community power.

The modeling of main risks results from deconstructing themultifaceted displacement process 
into its essential and most general risks of, namely:

1. Landlessness.

2. J oblessness.

3. Homelessness.

4. Marginalization.

5. Increased morbidity and mortality.

6 . Food insecurity.

7. Loss of access to common property.

8. Social (community) disarticulation.

Each of these is briefly presented below. Further, we will point out how the IRR Model is to be turned on its head to help derive counter-risk strategies and to match project measures against each of these eight basic risks.

1. Landlessness. Expropriation of land needed for the project's 'right of way' removes the main foundation on which many people build productive systems, commercial activities and livelihoods. Often land is lost forever, sometimes it is partially replaced, and only seldom fully replaced or fully compensated. This is the main form of decapitalization and pauperization of the people who are displaced. Both natural and man-made capital are lost.

2. J oblessness. Loss of wage employment occurs both in rural and urban displacement. People losing jobs may be landless agricultural laborers, service workers or artisans. The unemployment or underemployment among resettlers may linger long after physical relocation. Creating new jobs for them is difficult and requires substantial investment, new creative approaches and relying more on sharing project benefits.

3. Homelessness. Loss of housing and shelter may be only temporary for many people, but for some it remains a chronic condition and is felt as loss of identity and cultural impoverishment. Loss of dwelling may have consequences on family cohesion and mutual help patterns if neighboring households of the same kinship group get scattered. Group relocation of related people and neighbors is therefore preferable over dispersed relocation.

4. Marginalization. Marginalization occurs when relocated families lose economic power and slide down towards lesser socioeconomic positions: middle income farmhouseholds become small landholders; small shopkeepers and craftspeople lose business and fall below poverty thresholds. Economic marginalization is often accompanied by social and psychological marginalization, expressed in a drop in social status, in resettlers' loss of confidence in themselves and in society.

5. Increased morbidity and mortality. The vulnerability of the poorest people to illness is increased by forced relocation, as it tends to be associated with increased stress, psychological traumas, and the outbreak of parasitic and vector-born diseases. Serious decreases in health levels result from unsafe water supply and sewage systems that transmit epidemic infections, diarrhea, dysentery, etc., and may lead to higher mortality rates among children and the elderly.

6. Food insecurity. Forced uprooting diminishes self-sufficiency, dismantles local arrangements for food supply and, thus, increases the risk that people will fall into chronic food insecurity. This is defined as calorie-protein intake levels below the minimum necessary for normal growth and work.

7. Loss of access to common property. Poor farmers loose access to the common property assets belonging to communities that are relocated (e.g., loss of access to forests, water bodies, grazing lands, etc.). This type of income loss and livelihood deterioration is usually overlooked by planners and remains uncompensated.

8. Social disarticulation. The dismantling of community structures and social organization, the dispersation of informal and formal networks, local associations, etc., is a massive loss of social capital. Such disarticulation undermines livelihoods in ways not recognized and not measured by planners, and results in disempowerment and further pauperization.

The risks discussed above affect non-uniformly various categories of people: rural and urban, tribal and non-tribal groups, children and the elderly, or, in river based projects, upstream and downstream people. Research findings show that women suffer the impacts of displacement more severely than men. Host populations are also subjected to new risks, resulting from increased population densities and competition for resources

\section{How to reverse risks and reconstruct?}


Before displacement actually begins, the social and economic risks of impoverishment are only potential, possible risks. But if preventative counteractions are not initiated, these potential hazards convert into actual, dire impoverishment processes.

Robert K. Merton has insightfully observed that the prediction of an undesirable chain of events may become a 'self-destroying prophecy' (Merton 1979) if people respond adequately to the prediction. It follows that a risk prediction model becomes maximally useful not when it is confirmed by adverse events, but rather when, as a result of its warnings being taken seriously and acted upon, the risks are preempted from becoming reality, or are minimized. The prophecy destroys itself, and the consequences announced by the model do not occur or occur in a limited way.

The internal logic of the IRR Model as a planning tool suggests that in order to defeat its impoverishment prediction it is necessary to attack the looming risksearly on during the preparation of a development project. In the same way in which it deconstructs the process of displacement into eight major risks of impoverishment, the IRR Model also deconstructs the process of resettlement and reconstruction into a set of definable risks-reversal activities, able to lead:

- from landlessness to land-based resettlement,

- from joblessness to reemployment,

- from homelessness to house reconstruction,

- from marginalization to social inclusion,

- from increased morbidity to improved health care,

- from food insecurity to adequate nutrition,

- from loss of access to restoration of community assets and services, and

- from social disarticulation to rebuilding networks and communities.

These strategic directions for reconstruction indicate that the IRR Model is not just a predictor of inescapable pauperization: on the contrary, it maps the way to restoring and improving thelivelihoods of the displaced. Like in the case of other models, the components of the IRR Model can be acted upon and influenced through planning and resource allocation, in order to diminish the impact of one or several risks.

\section{Risk-reduction through policy measures}

Development knowledge teaches us that measures to reduce risks can be taken both at the project level, and at the policy level. For instance, policies that keep the costs of energy too low tend to encourage overconsumption and tolerate waste, thus leading to constructing more dams or thermal plants, with entailed displacements risks. This suggests that the risks of resettlement can be diminished also through better demand-management policies. Ultimately, the interlocked risks inherent in displacement can be controlled when governments adopt broad national policies for safety nets and risk reversals. Single means-for instance, cash compensation-are insufficient to alone counterbalance all risks. Compensation needs to be supplemented with special investments directed to the resettled communities, and with sharing with the resettlers a part of the benefits generated by the project that displaces them. Without substantial financing, no sound and sustainable resettlement is possible. ${ }^{1}$

Maximum safeguarding is achieved when involuntary displacement is avoided altogether. This is the response to risks that should be considered first and foremost. Recognizing risks upfront and their financial implications is often a powerful stimulus to search for an alternative that will eliminate the need for displacement or cut down its size. This is technically possible in some cases, for instance, by changing the site of a dam or by re-routing a highway around (rather than through) a village. Many other technical options can be found through creative search.

Social research on resettlement has indeed identified specific risk management strategies that can be employed against the common risks in resettlement, to prevent landlessness, joblessness, higher morbidity, etc. In turn, social research on voluntary settlement schemes and on patterns of selfmanagement after relocation has documented effective approaches, some replicable in involuntary resettlement, that can help those resettling to new lands to overcome the risks and difficulties of resettlement. $^{2}$

Michael M. Cernea is Research Professor of Anthropology and International Affairs at George Washington University, Washington DC, and also serves as Senior Social Adviser to the Evaluation Office of the Global Environmental Facility. Hejoined the World Bank as its first sociologist in 1974 and has developed and led a professional group of sociologists and anthropologists for over 20 years the Bank's Senior Adviser for Social Policies. Dr. Cernea wrote the policy on involuntary population resettlement in development programs of the World Bank (in 1979) and of OECD countries' aid agencies (in 1991). Prof. Cernea contributed to the construction of the Kali Gandaki Dam in Nepal in his capacity as Member of the project'si International Panel of Experts for Resettlement and Environment, making eight field-work assessments and advising project management and the Nepal Electricity Authority. He has published numerous books and hundreds of articles, taught in 
Universities in Europe, Asia and the US, and has served as advisor on social policy, resettlement, cultural heritage and poverty issues to many international organizations, including ADB, CGIAR, UN, FAO and OECD.

Corresponding address: mcernea@worldbank.org

\section{End notes}

1. For a more detailed argument, see Cernea 2007.

2. For empirical documentation on the impoverishment risks and impacts, as well as on results of risks reduction measures, please consult the recommended readings (see References).

\section{References}

Cernea, Michael M. and McDowell, C. (eds.), 2000, Risks and Reconstruction: Experiences of Resettlers and Refugees, Washington, DC: The World Bank.

Cernea, Michael M., 1991, Involuntary resettlement: Social research, policy and planning, pp.188-216 in M.M. Cernea (ed.), Putting People First: Sociological Variables in Development, NewYork and London: Oxford University Press.

_ , 2007, Financing of development and benefitsharing mechanisms in population resettlement, Economic and Political Weekly, 42(12):10331046. URL: www.epw.org.in.

Mahapatra, L.K., 1998, Resettlement, Impoverishment and Reconstruction in India, New Delhi: Vikas.

Mathur, H.M. and Marsden, David (eds.), 1998, Development Projects and Impoverishment Risks: Resettling Projects Affected People, Oxford, UK: Oxford University Press.

Merton, Robert K., 1979, The Sociology of Science: Theoretical and Empirical Investigations, Chicago: University of Chicago Press. 